\title{
Development of microsatellite markers for Suriana maritima (Surianaceae) using next- generation sequencing technology
}

\author{
W.S. Chen ${ }^{1,2}$, G. Zhao ${ }^{2}$, S.G. Jian ${ }^{1}$ and Z.F. Wang ${ }^{1}$ \\ ${ }^{1}$ South China Botanical Garden, Chinese Academy of Sciences, Guangzhou, China \\ ${ }^{2}$ Zhongkai University of Agriculture and Engineering, Guangzhou, China
}

Corresponding author: S.G. Jian / Z.F. Wang

E-mail: jiansg@scbg.ac.cn / wzf@scib.ac.cn

Genet. Mol. Res. 14 (4): 14115-14118 (2015)

Received May 29, 2015

Accepted August 28, 2015

Published October 29, 2015

DOI http://dx.doi.org/10.4238/2015.October.29.31

\begin{abstract}
Our objective was to develop microsatellite markers for use in assessing genetic variation in the small shrub or tree species Suriana maritima (Surianaceae). In China, this species is found only as a few fragmented populations and individuals on the Paracel Islands. Using next-generation genome sequencing methodology, we developed 17 novel microsatellite markers for S. maritima. Fifty-four individuals from six populations of $S$. maritima were examined for polymorphisms; only one allele was detected for each of the markers. Microsatellite loci developed indicate a complete absence of genetic diversity for $S$. maritima on the Paracel Islands in China. These markers will be useful for examining genetic variation among S. maritima populations in other areas of the world.
\end{abstract}

Key words: Suriana maritima; Surianaceae; Microsatellite markers; Next-generation sequencing; Paracel islands 
W.S. Chen et al.

\section{INTRODUCTION}

Suriana maritima L., the sole species of Suriana (Surianaceae), grows as a perennial shrub or small tree on tropical Pacific coral islands, such as those of India, Indonesia, Philippines, and China. Usually, it grows in sandy areas or in crevices along the edges of such islands (Peng and Thomas, 2008). In China, S. maritima is restricted to the Paracel Islands, where only a few fragmented populations and individuals exist, because of the effects of climate change and human activity (Tong et al., 2013).

The taxonomic status of $S$. maritima among angiosperms has been controversial (Gutzwiller, 1961; Cronquist, 1981; Thome, 1983; Takhtajan, 1987; Fernando et al., 1992; Peng and Thomas, 2008; Bremer et al., 2009). At various points, S. maritima has been placed in the Phytolaccaceae (Gutzwiller, 1961), the Simaroubaceae (Cronquist 1981), and the Surianaceae (Thome, 1983; Fernando et al., 1992; Peng and Thomas, 2008). Takhtajan (1987) suggested placement of Surianaceae (including S. maritima) and Simaroubaceae in Rutales. Cronquist (1988) placed Surianaceae (including S. maritima) in Rosales. Bremer et al. (2009) suggested placement of Surianaceae (with five genera and eight species, including S. maritima), Polygalaceae, Quillajaceae, and Leguminosae in Fabales, and considered Surianaceae as sister to Polygalaceae. Therefore, S. maritima is an interesting species for the phylogenetic study of the Surianaceae and Fabales (including the Surianaceae, Polygalaceae, Quillajaceae, and Leguminosae) (Bremer et al., 2009).

Little is known about genetic variations among S. maritima populations and individuals in China, or in other areas of the world. In this study, we used next-generation sequencing to develop microsatellite markers, in order to assess genetic variation in S. maritime. Markers were used to analyze 54 individual S. maritima plants from six populations on the Paracel Islands.

\section{MATERIAL AND METHODS}

Leaf samples of $S$. maritima on the Paracel Islands, China, were collected from six populations: Chenhang $(\mathrm{CH})$; Yongxing (YX); Guangjin (GJ); Dongdao (DD); Zhongjian (ZJ; all $N=10$ ); and Jinyin (JY, $N=4$; Table S1). Total genomic DNA was extracted from silica geldried leaf tissue, as previously described (Doyle and Doyle, 1987). One DNA sample from the ZJ population was subjected to restriction-site-associated DNA sequencing (RAD-seq), using a HiSeq2000 sequencer (Illumina, Inc., San Diego, California,USA). A total of 112,999 reads were obtained, and assembled using STACK version 1.24 (Catchen et al., 2011; 2013). A total of 473 microsatellites (di-, tri- and tetranucleotide; minimum of six repeats) were identified using MSATCOMMANDER software, version 0.8 .2 (Faircloth, 2008); only 80 of these could be used for primer design, which was carried out using the program Primer3 (Rozen and Skaletsky, 2000) embedded in MSATCOMMANDER. Primers were tagged with the universal M13 sequence (GTAAAACGACGGCCAGT). Thirteen primers were discarded due to the complexity of their repeat motifs. Ultimately, 67 microsatellite loci were selected for subsequent testing with 12 individuals from the six populations (two for each population).

Amplifications by PCR were conducted in $10-\mu \mathrm{L}$ total volume reactions that contained: 10 ng template DNA; $2 \mu \mathrm{L}$ 10X buffer (Takara Biotechology (Dalian) Co., LTD., Dalian, China); 0.4 mM dNTPs; $10 \mathrm{mM} \mathrm{MgCl}$; $0.5 \mathrm{U}$ Taq DNA polymerase (Takara); $0.05 \mathrm{mM}$ forward primer; $1.5 \mathrm{mM}$ reverse primer; and $1.5 \mathrm{mM}$ fluorescently labeled M13 primer. Amplifications were carried out in 
a PTC-100 thermo cycler (MJ Research Inc., St. Bruno, Canada) under the following conditions: a melting step of $94^{\circ} \mathrm{C}$ for $5 \mathrm{~min} ; 35$ cycles at $94^{\circ} \mathrm{C}$ for $30 \mathrm{~s}$, annealing temperatures (as per Table 1) for $60 \mathrm{~s}$, and $72^{\circ} \mathrm{C}$ for $30 \mathrm{~s}$; and a final extension at $72^{\circ} \mathrm{C}$ for $10 \mathrm{~min}$. Amplified products were assessed on $2 \%$ agarose $(\mathrm{w} / \mathrm{v})$ gel. Amplification products were visualized using the genetic analyzer ABI3500 (Applied Biosystems, Carlsbad, California, USA), and the results were analyzed using GeneMapper 4.1 (Applied Biosystems).

Table 1. Characteristics of microsatellite markers for Suriana maritima.

\begin{tabular}{|c|c|c|c|c|c|c|c|c|}
\hline Locus & Primer sequence $\left(5^{\prime}-3^{\prime}\right)$ & Repeat motif & Size (bp) & $T_{a}\left({ }^{\circ} \mathrm{C}\right)$ & $\mathrm{N}$ & $H_{0}$ & $H_{E}$ & GenBank accession No. \\
\hline \multirow[t]{2}{*}{ s1 } & F: ACATTGGTGCATGCGTTGG & & & & & & & \\
\hline & R: AGGCCTTGGTTTAGTACCC & $(\mathrm{AC})_{9}$ & 202 & 48 & 1 & 0.000 & 0.000 & KP717426 \\
\hline \multirow[t]{2}{*}{ s5 } & F: ACCAGCACAATGAAGTTGGC & & & & & & & \\
\hline & R: AGAAGTTTGGTTATGCTGCG & $(A G)_{11}$ & 195 & 47 & 1 & 0.000 & 0.000 & KP717427 \\
\hline \multirow[t]{2}{*}{ s6 6} & F: TTTAGTGCACAGCCACGTC & & & & & & & \\
\hline & R: AACAAGGCCCTGAACGGAG & $(\mathrm{AG})_{10}$ & 318 & 56 & 1 & 0.000 & 0.000 & KP717428 \\
\hline \multirow[t]{2}{*}{ s7 } & F: GCCAGTTGTCGAATGCCTC & & & & & & & \\
\hline & R: AGGAAGATCTCACTGAAACAAAGTC & $(\mathrm{CT})_{6}(\mathrm{CA})_{13}$ & 152 & 48 & 1 & 0.000 & 0.000 & KP717429 \\
\hline \multirow[t]{2}{*}{ s9 } & F: TAGCGATCGAGGCCTTTGG & & & & & & & \\
\hline & R: AAATTCCAGGACAGGTGCG & $(\mathrm{AG})_{12}$ & 219 & 60 & 1 & 0.000 & 0.000 & KP717430 \\
\hline \multirow[t]{2}{*}{ s12 } & F: TGATGGTACAGCAAGTGGG & & & & & & & \\
\hline & R: GCAACAAATAGCAAGCCCAAAG & $(\mathrm{GT})_{11}(\mathrm{GA})_{7}$ & 347 & 56 & 1 & 0.000 & 0.000 & KP717431 \\
\hline \multirow[t]{2}{*}{ s13 } & F: TCCAAACAATAAACAATGTCCATCC & & & & & & & \\
\hline & R: ATGTGAGCACTTCCTGCCC & $(\mathrm{CT})_{10}$ & 228 & 56 & 1 & 0.000 & 0.000 & KP717432 \\
\hline \multirow[t]{2}{*}{ S21 } & F: TCCTTGGTTGGAGAATTGTTGC & & & & & & & \\
\hline & R: ACAGAGTACACAAGGATCAAGTG & $(\mathrm{CT})_{9}$ & 207 & 47 & 1 & 0.000 & 0.000 & KP717433 \\
\hline \multirow[t]{2}{*}{ S22 } & F: AGTTGTTTAGTCATAGCAAACTGTC & & & & & & & \\
\hline & R: CATTAATTGACCTTTGATGGGTTC & $(\mathrm{AG})_{6} \mathrm{TG}(\mathrm{AG})_{9}$ & 193 & 48 & 1 & 0.000 & 0.000 & KP717434 \\
\hline \multirow[t]{2}{*}{ s23 } & F: CCTTTGCAGGTACGTGAGC & & & & & & & \\
\hline & R: TCACTAACACCCTATTTAAGCAC & $(\mathrm{ACT})_{8}$ & 178 & 60 & 1 & 0.000 & 0.000 & KP717435 \\
\hline \multirow[t]{2}{*}{ S27 } & F: AACAACATTGCAGCTTGGG & & & & & & & \\
\hline & R: CATTGGCTGCGTAGTTGCC & $(A G)_{10}$ & 173 & 47 & 1 & 0.000 & 0.000 & KP717436 \\
\hline \multirow[t]{2}{*}{ s36 } & F: CAACTTCCTGAACACCGAGC & & & & & & & \\
\hline & R: TGGTGGTAAAGGCCCTAGTC & $(\mathrm{GT})_{10}$ & 300 & 58 & 1 & 0.000 & 0.000 & KP717437 \\
\hline \multirow[t]{2}{*}{ s37 } & F: CCACCCTACGGTATTGAAGC & & & & & & & \\
\hline & R: TCCGATCTTGAATATTGCTCGAC & $(\mathrm{CT})_{12}$ & 272 & 49 & 1 & 0.000 & 0.000 & KP717438 \\
\hline \multirow[t]{2}{*}{ s39 } & F: ACAGACCACATCGGAAGCC & & & & & & & \\
\hline & R: AGGCGCCCATCCTTTGTC & $(\mathrm{AG})_{9}$ & 274 & 58 & 1 & 0.000 & 0.000 & KP717439 \\
\hline \multirow[t]{2}{*}{ S42 } & F: TCAAAGGCAATTGAGGCTGTC & & & & & & & \\
\hline & R: GGTGACACTCCTCACCAAG & $(\mathrm{GT})_{10}$ & 363 & 58 & 1 & 0.000 & 0.000 & KP717440 \\
\hline \multirow[t]{2}{*}{ S43 } & F: ACCCGGGACATTTCTATTGG & & & & & & & \\
\hline & R: TGTATGAATTGTTGAACCCTTGG & $(A G)_{13}$ & 208 & 47 & 1 & 0.000 & 0.000 & KP717441 \\
\hline \multirow[t]{2}{*}{ S51 } & F: CTACAAACCAATCCACCGC & & & & & & & \\
\hline & R: TGTGTTCTTCGCAGACTTAGC & $(G T)_{8}(G A)_{10}$ & 196 & 58 & 1 & 0.000 & 0.000 & KP717442 \\
\hline
\end{tabular}




\section{RESULTS AND DISCUSSION}

Polymorphisms were assessed for the remaining 17 microsatellite loci using all 54 samples from the six populations. Among 67 microsatellite loci tested, 40 failed to amplify correctly in all samples, and 10 produced blurred bands. All loci were found to be monomorphic within and among populations, indicating a complete absence of genetic variation among S. maritima in China (Table 1). This lack of genetic variation may be the result of a recent founder effect or bottleneck, because of recent introduction and a single ancestor. Furthermore, repeated selfing and inbreeding would be also responsible further loss of genetic diversity of $S$. maritima in this study. These markers will be useful for assessing genetic variation among S. maritima populations in other parts of the world.

\section{Conflicts of interest}

The authors declare no conflict of interest.

\section{ACKNOWLEDGMENTS}

The authors thank Tong Yi and Chen Quan for assistance with sample collection. This study was supported by the National Science and Technology Infrastructure Program of China (grant No. 2013FY111200).

\section{Supplementary material}

\section{REFERENCES}

Bremer B, Bremer K, Chase M, Fay M, et al. (2009). An update of the Angiosperm Phylogeny Group classification for the orders and families of flowering plants: APG III. Bot. J. Linn. Soc. 161: 105-121.

Catchen JM, Amores A, Hohenlohe P, Crecko W, et al. (2011). Stacks: building and genotyping loci de novo from short-read sequences. G3 (Bethesda) 1: 171-182.

Catchen J, Hohenlohe PA, Bassham S, Amores A, et al. (2013). Stacks: an analysis tool set for population genomics. Mol. Ecol. 22: 3124-3140.

Cronquist A (1981). An integrated system of classification of flowering plants. Columbia University Press, New York.

Cronquist A (1988). The evolution and classification of flowering plants. 2nd edn. New York Botanical Garden, New York.

Doyle JJ and Doyle JL (1987). A rapid DNA isolation procedure for small quantities of fresh leaf tissue. Phytochem. Bull. 19: 11-15.

Faircloth BC (2008). MSATCOMMANDER: detection of microsatellite repeat arrays and automated, locus-specific primer design. Mol. Ecol. Resour. 8: 92-94.

Fernando ES and Quinn CJ (1992). Pericarp anatomy and systematics of the Simaroubaceae Sensu lato. Aust. J. Bot. 40: 263-289.

Gutzwiller MA (1961). Die phylogenetische Stellung von Suriana maritima L. Dissertation. Aus: Botanische Jahrbücher Bd. 81. Zurich, 1-49.

Peng $\mathrm{H}$ and Thomas WW (2008). Surianaceae. In: Flora of China: Oxalidaceae through Aceraceae (Wu ZY and Raven PH, eds.). Missouri Botanical Garden Press, St. Louis, 105.

Rozen S and Skaletsky H (2000). Primer3 on the WWW for general users and for biologist programmers. Methods Mol. Biol. 132: 365-386.

Takhtajan A (1987). Systema Magnoliophytorum. Soviet Sciences Press, Nakua, Leningrad.

Thome RF (1983). Proposed new realignments in the angiosperms. Nord. J. Bot. 3: 85-117.

Tong Y, Jian SG, Chen Q, Li YL, et al. (2013). Vascular plant diversity of Paracel Islands, China. Biodiver. Sci. 21: 364-374. 